\title{
Voltage Clamp Analysis of Cholinergic Action in the Hippocampus
}

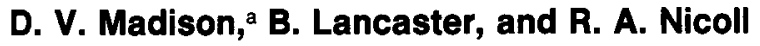 \\ Departments of Pharmacology and Physiology, University of California, San Francisco, California 94143
}

\begin{abstract}
A slow muscarinic EPSP, accompanied by an increase in membrane input resistance, can be elicited in hippocampal CA1 pyramidal cells in vitro by electrical stimulation of cholinergic afferents in the slice preparation. Associated with the slow EPSP is a blockade of calcium-activated potassium afterhyperpolarizations (AHPs) (Cole and Nicoll, 1984a). In this study a single-electrode voltage clamp was used to examine the currents affected by activation of muscarinic receptors, using either bath application of carbachol or electrical stimulation of the cholinergic afferents. The 3 main findings of this study are that (1) of the 2 calcium-activated potassium currents (termed $I_{A M P}$ and $I_{C}$ ) in hippocampal pyramidal cells, only $I_{\text {AHP }}$ is sensitive to carbachol; (2) $I_{\text {AHP }}$ is approximately 10 -fold more sensitive to carbachol than is another muscarine-sensitive current, $I_{m}$; and (3) neither blockade of $I_{\text {AHP }}$ nor of $I_{M}$ can account for the production of the slow EPSP. Rather, the slow EPSP appears to be generated by the blockade of a nonvoltage-dependent, resting potassium current. We propose that the muscarinic blockade of $I_{A H P}$, which largely accounts for spike frequency adaptation, is primarily involved in enhancing action potential discharge to depolarizing stimuli, while the slow EPSP acts directly to cause action potential discharge.
\end{abstract}

Hippocampal pyramidal cells receive a well-defined cholinergic synaptic input from neurons in the medial septum (Lewis and Shute, 1967; Nicoll, 1985). Intracellular recording from pyramidal cells in the in vitro slice preparation has revealed that acetylcholine, acting on muscarinic receptors, causes (1) a depolarization of the membrane potential associated with an increase in input resistance (Dodd et al., 1981; Benardo and Prince, 1982; Cole and Nicoll, 1984a, b); (2) a blockade of the slow afterhyperpolarization (AHP) that follows action potentials (Benardo and Prince, 1982; Cole and Nicoll, 1984a, b); and (3) blockade of a voltage-dependent current termed the $M$ current $\left(I_{M}\right)(\mathrm{Hal}-$ liwell and Adams, 1982). Current clamp studies in pyramidal cells have established that repetitive electrical stimulation in certain areas of the slice can reproduce the muscarinic membrane depolarization and the blockade of the AHP (Cole and Nicoll, 1984a). However, it is not known what membrane cur-

\footnotetext{
Received Apr. 30, 1986; revised Sept. 22, 1986; accepted Oct. 17, 1986.

This work was supported by Grants MH-38256, MH-00437 (RCDA to R.A.N.), the Scottish Rite Schizophrenia Research Program, NMI, USA, and the Klingenstein Fund. We wish to thank Dr. Paul Adams for his constructive comments during the course of this study, which was initiated while B.L. was on loan from his laboratory.

Correspondence should be addressed to Dr. R. A. Nicoll, Department of Pharmacology, S-1210, University of California, San Francisco, CA 94143.

a Present address: Department of Physiology, Yale University School of Medicine, New Haven, CT 06510

Copyright $(\mathcal{C} 1987$ Society for Neuroscience $0270-6474 / 87 / 030733-10 \$ 02.00 / 0$
}

rents underlie these actions of acetylcholine. In the present study we have used a single electrode voltage clamp to study the sensitivity of membranc currents to muscarinic receptor stimulation, both by bath applications of the cholinomimetic carbachol and by synaptically released acetylcholine. Some of these results have appeared in abstract form (Madison et al., 1985).

\section{Materials and Methods}

The experiments in this paper were performed on hippocampal slices, in vitro, prepared by standard methods (Nicoll and Alger, 1981; Madison and Nicoll, 1986a). During experiments, slices were maintained in the recording chamber, completely submerged beneath a continuously superfusing medium. This medium consisted of (in $\mathrm{mm}$ ): $\mathrm{NaCl}, 119 ; \mathrm{KCl}$, $2.5 ; \mathrm{MgSO}_{4}, 1.3 ; \mathrm{CaCl}_{2}, 2.5 ; \mathrm{NaH}_{2} \mathrm{PO}_{4}, 1 ; \mathrm{NaHCO}_{3}, 26.2$; and glucose 11 pregassed with $95 \% \mathrm{O}_{2}, 5 \% \mathrm{CO}_{2}$. Intracellular current-clamp and single-electrode voltage-clamp recordings were made from CAl pyramidal cells using either an Axoclamp II or a Dagan 8100 single-electrode voltage clamp. The recording methods were the same as those described previously by Lancaster and Adams (1986) and Madison and Nicoll (1986a), with the following modifications. To record the effects of bathapplied drugs, $\mathrm{KCl}(3 \mathrm{M})$-filled microelectrodes (20-80 M $)$ were used and TTX was added to the superfusate to block spontaneous inhibitory postsynaptic currents (IPSCs). Since TTX could not be used when recording evoked synaptic currents, $\mathrm{K}$ methylsulfate $(2 \mathrm{M})$-filled microelectrodes $(70-100 \mathrm{M} \Omega)$ were usually used to avoid the spontaneous IPSCs recorded with KCl-filled microelectrodes. In some experiments dealing with the membrane current underlying the slow afterhyperpolarization, a hybrid current/voltage clamp protocol was used (see Pennefather et al., 1985; Lancaster and Adams, 1986). In this protocol, a cell recorded in the current clamp mode was stimulated to discharge a train of action potentials by the passage of a brief $(\sim 50 \mathrm{msec})$ depolarizing current through the recording electrode. A slow AHP normally follows such a stimulus. Immediately following the end of the current stimulus, the amplifier was switched from current clamp to voltage clamp mode to record the AHP current. In some experiments the same current was elicited by making short-duration depolarizing steps entirely in the voltage clamp mode. The technique of single electrode voltage clamp is associated with the persistent problem of the decrement in voltage control, which is inevitable in a cell with extended processes. For example, applied voltage steps will be attenuated at sites that are not isopotential with the soma; the measured current may not be the appropriate one for the applied voltage command, and the conductancevoltage relation will be underestimated. Important as these problems are, it is more difficult to account for purely qualitative differences, arising from drug application, with arguments about spatial considerations. For a more detailed discussion of the limitations of voltage clamping a neuron with extensive processes, the reader is referred to Halliwell and Adams (1982) and Johnston and Brown (1983).

Slow EPSPs and EPSCs were elicited by methods described previously (Cole and Nicoll, 1984a). Briefly, a bipolar stimulating electrode was placed in stratum oriens of the slice, where cholinergic septal afferents coursc. Bricf tctanic stimuli $(30-40 \mathrm{~Hz}$ for $0.5 \mathrm{sec}$ ) produced a serics of fast, noncholinergic EPSPs and IPSPs, followed by the slow muscarinic EPSP. In voltage clamp, during the slow muscarinic EPSC, voltage steps were made to determine the effects of synaptically released acetylcholine on membrane currents.

The drugs used in this study, which were purchased from Sigma, were carbamyl choline chloride (carbachol), cadmium chloride, atropine sulfate, eserine chloride, 8 -bromoadenosine $3^{\prime}, 5^{\prime}$-monophosphate (8-bro- 

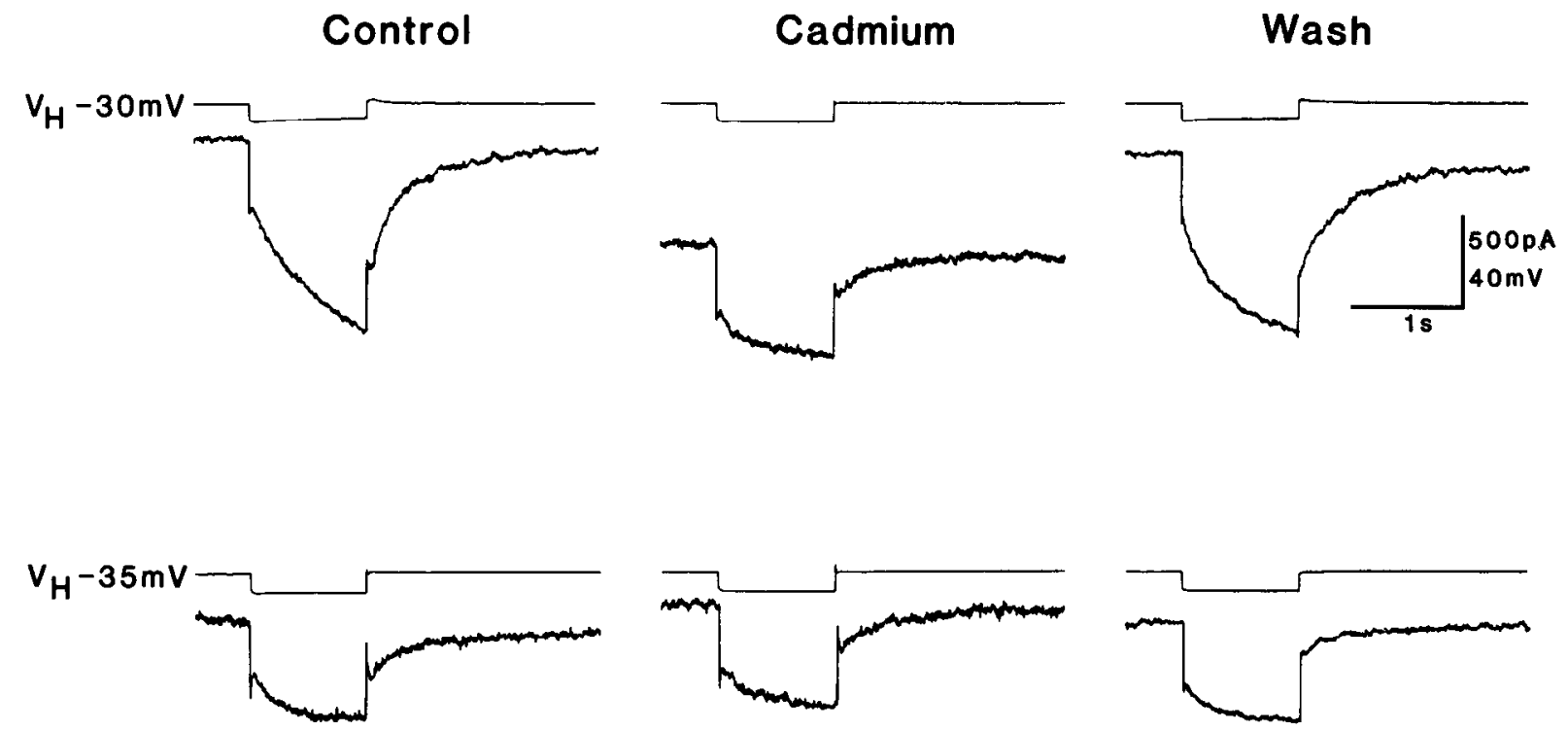

Figure 1. Cadmium-sensitive current at depolarized membrane potentials in CAl pyramidal cells. All records in this figure are from the same pyramidal cell bathed in $1 \mu \mathrm{M}$ TTX. When holding the cell in voltage clamp at $-35 \mathrm{mV}, 10 \mathrm{mV}$ hyperpolarizing steps produced a time-dependent inward current that was due to the voltage-dependent deactivation of $M$ current, as reported previously (Halliwell and Adams, 1982). Making a similar voltage step from a holding potential only $5 \mathrm{mV}$ more depolarized produced a much larger inward current that had much slower kinetics than the M current. Application of the calcium channel blocker cadmium (100 $\mu \mathrm{M}$ for $20 \mathrm{~min}$ ) caused an inward current at a holding potential of $-30 \mathrm{mV}$ and abolished most of this slow inward current, leaving a current relaxation with kinetics similar to those of $\mathrm{I}_{\mathrm{M}}$. Since this slow inward current, in addition to its sensitivity to calcium channel blockade, was accompanied by a decrease in membrane conductance, it is likely to have been due to the turning off of a steady calcium-dependent potassium current. This current was presumably activated at around - $30 \mathrm{mV}$, when the high-threshold, slowly inactivating calcium current described in these cells was turned on.

mo cyclic AMP), tetraethylammonium chloride (TEA), and TTX (Calbiochem), all of which were applied in the superfusing medium. Cyclic AMP was injected into some cells through the recording electrode $(100$ $\mathrm{mm}$ added to the normal recording electrolyte, either $2 \mathrm{M}$ potassium methylsulfate or $3 \mathrm{M} \mathrm{KCl}$ ).

\section{Results}

\section{Membrane currents and their sensitivity to carbachol}

Though the goal of these experiments was to shed further light on the actions of the cholinomimetic carbachol and synaptically rclcased ACh on membrane currents in hippocampal CAl pyramidal neurons, we first performed experiments to identify membrane currents that might act as substrates for cholinergic action. At least 2 such currents are apparent in the data presented in Figure 1. When the membrane potential of pyramidal cells is held in voltage clamp at potentials between -35 and -45 $\mathrm{mV}$, hyperpolarizing voltage steps produce time-dependent inward current relaxations, accompanied by a decrease in membrane conductance (Fig. 1, bottom). These current relaxations are due to the voltage-dependent deactivation of a potassium current known as $I_{M}$. The properties of this current, including its sensitivity to muscarinic agonists, have been described previously (Halliwell and Adams, 1982). However, when the holding potential $\left(V_{H}\right)$ is adjusted to a level near $-30 \mathrm{mV}$, there is a dramatic change in the character of the inward relaxations produced by hyperpolarization. While such current relaxations are still accompanied by a decrease in membrane conductance, they are very much larger and slower than the currents elicited from holding potentials a few millivolts more hyperpolarized (Fig. 1, left).

We hypothesized that this slow current relaxation at depolarized potentials might be caused by the turning off of a calcium-activated potassium current that is active at depolarized levels where there is a steady influx of calcium. It is known from previous studies that a slow or noninactivating calcium current is activated in pyramidal cells at potentials near $-30 \mathrm{mV}$ (Johnston et al., 1980; Brown and Griffith, 1983b; Madison and Nicoll, 1986a). This calcium current $\left(\mathrm{I}_{\mathrm{Ca}}\right)$ would in turn activate calcium-dependent potassium currents and, indeed, as the holding potential is adjusted to depolarized levels near $-30 \mathrm{mV}$, a large outward current develops. Thus, it seems likely that by holding a pyramidal cell at potentials near $-30 \mathrm{mV}$, a steady calcium-dependent potassium current is generated, and this current is turned off by hyperpolarization. In support of this idea, we have found (Fig. 1, top) that bathing the preparation in the calcium channel blocker cadmium produces a large inward shift in holding current at $-30 \mathrm{mV}$ and reduces the hyperpolarization-induced slow inward relaxation at this $\mathrm{V}_{\mathrm{H}}$. Cadmium had no effect on $I_{M}$, and the inward relaxations seen at a holding potential at $-30 \mathrm{mV}$ in the presence of cadmium closely resembles the $I_{M}$ seen at a holding potential of $-35 \mathrm{mV}$. When the membrane potential was held more positive than about -35 $\mathrm{mV}$, the cadmium-sensitive outward current had a tendency to run down over a period of $20-30 \mathrm{sec}$. This was evident as a slow inward drift in holding current and a reduction in the calcium-dependent outward current evoked by voltage steps. This conceivably represented some inactivation process, since the current would recover upon holding the membrane potential more negative. Therefore, the cell was held at $-60 \mathrm{mV}$ for a few minutes prior to each activation of this current.

It should be possible, given the above data, to activate this calcium-dependent potassium current by holding just below the threshold for $\mathrm{I}_{\mathrm{Ca}}$ and making depolarizing steps into the range where $\mathrm{I}_{\mathrm{Ca}}$ is activated. Indeed, such a protocol produces a large outward current (Fig. $2 A_{1}$ ). This current can be compared to $\mathrm{I}_{\mathrm{M}}$, which can be seen by making hyperpolarizing steps from the 


\section{Control}

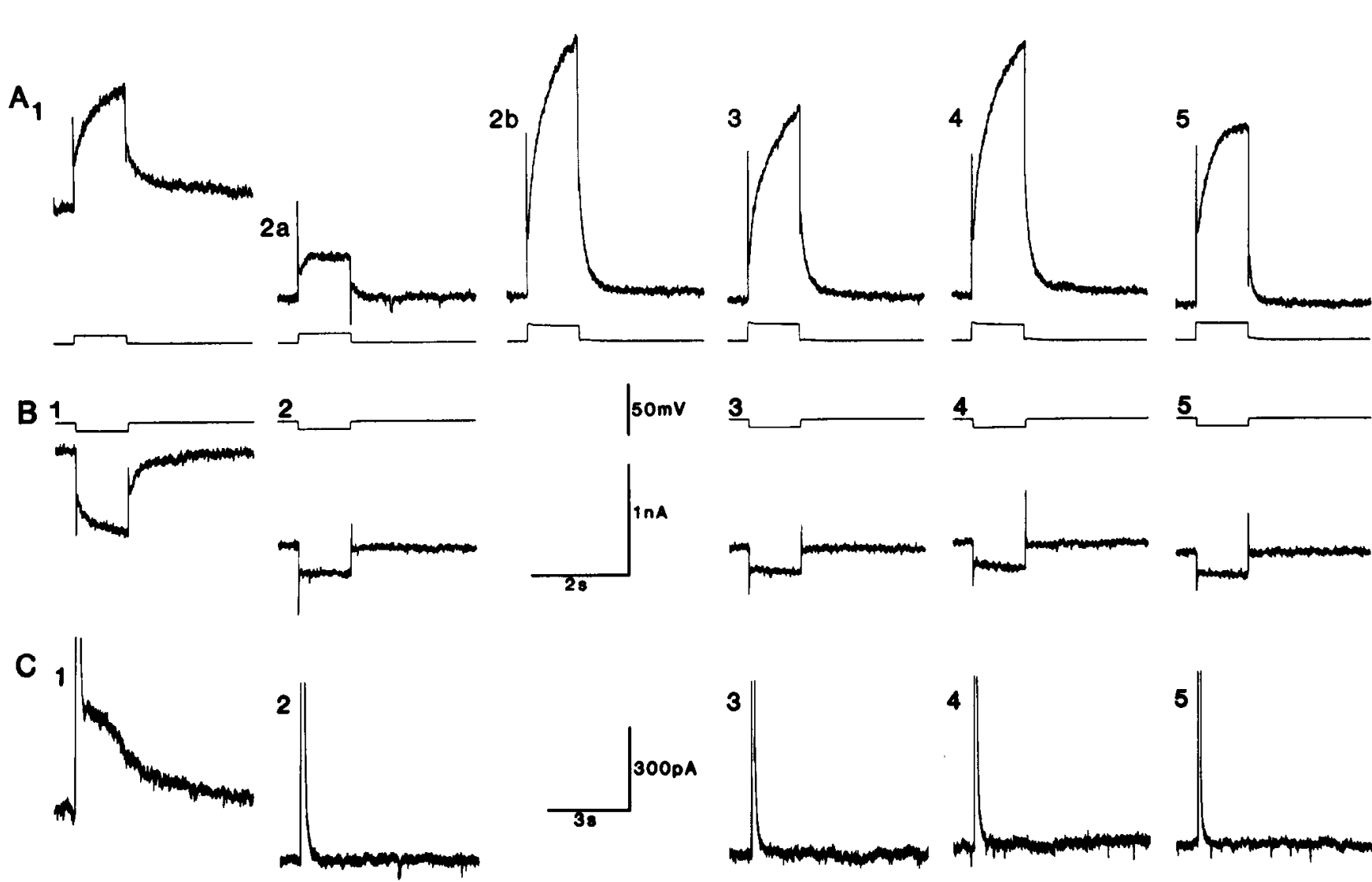

Figure 2. Carbachol sensitivity of $M$ current and of 2 calcium-activated potassium currents in CA1 pyramidal cells. All records in this figure are from the same pyramidal cell, bathed in $1 \mu \mathrm{M}$ TTX. $A_{l}$, Holding the cell in voltage clamp at $-40 \mathrm{mV}$ and making depolarizing voltage steps produced a slow outward current, followed by a slow outward tail current. $A_{2 a}$, Application of carbachol ( $\left.40 \mu \mathrm{M}\right)$ produced a large inward shift in holding current, and most of the voltage-dependent outward current was abolished. This high concentration of carbachol also abolished the $M$ current, seen with hyperpolarizing steps from the same holding potential $\left(-40 \mathrm{mV}, B_{1}\right.$ and $\left.B_{2}\right)$, and also the calcium-activated potassium current $\left(\mathrm{I}_{\mathrm{AH}}\right)$ that follows a short depolarization from a $\mathrm{V}_{\mathrm{H}}$ of $-60 \mathrm{mV}\left(C_{l}\right.$ and $\left.C_{2}\right)$. Even in the presence of carbachol, a large outward current could be elicited by making larger depolarizing steps from $-40 \mathrm{mV}\left(A_{2 b}\right)$. A substantial amount of this outward current was reversibly abolished by application of a low concentration (1 mM) of TEA $\left(A_{3}\right)$. This outward current was also sensitive to the calcium channel blocker cadmium (100 $\mu \mathrm{M}$ for 20 min; $A_{5}$ ), suggesting that it was due to a calcium-activated potassium current that was TEA-sensitive and insensitive to carbachol.

same holding potential $\left(\mathrm{V}_{\mathrm{H}},-40 \mathrm{mV}\right.$; Fig. $\left.2 B_{1}\right)$ and with the outward current that follows short-duration depolarizing pulses from a $V_{H}$ of $-60 \mathrm{mV}$. This latter current is known from previous reports to be due almost entirely to the calcium-dependent potassium conductance that underlies the slow AHP in these cells; it is known as $\mathrm{I}_{\mathrm{AHP}}$ (Fig. $2 C_{1}$ ) (Lancaster and Adams, 1986).

We tested the muscarinic sensitivity of the currents produced by the 3 protocols described above, using the agonist carbachol in high concentration $(40 \mu \mathrm{M})$. The $\mathrm{M}$ current (Fig. $\left.2 B_{2}\right)$ and $\mathrm{I}_{\mathrm{AHP}}$ (Fig. $2 C_{2}$ ) were largely abolished, and the outward current at depolarized levels (Fig. $2 A_{2 \mathrm{a}}$ ) was greatly reduced by this application of carbachol. The inward shift in holding current produced by carbachol is due to blockade of standing outward currents that are present at depolarized holding potentials. However, even in this high concentration of carbachol, some outward current remained during the depolarizing step, and a very large current could be produced in the presence of carbachol by making a slightly larger depolarizing step (Fig. $2 A_{2 \mathrm{~b}}$ ). The outward current that persists in a high dose of carbachol can be markedly reduced by a low concentration ( $1 \mathrm{mM}$ ) of TEA (Fig. $2 A_{3}$ ). In a previous report (Brown and Griffith, 1983a), a TEA and voltage- sensitive, calcium-dependent potassium current was described in hippocampal pyramidal cells and was termed $\mathrm{I}_{\mathrm{C}}$ by analogy with a similar current found in bullfrog ganglion cells (Adams et al., 1982).

In hippocampal neurons, $I_{C}$ has been shown to be sensitive to TEA, but not, apparently, to muscarinic receptor activation (Brown and Griffith, 1983a). Since the current that persists in carbachol resembles the $\mathrm{I}_{\mathrm{C}}$ described previously, we examined its sensitivity to the calcium channel blocker cadmium and found that the current was reduced to a similar degree as with TEA (Fig. 2A). Thus, the data in Figure 2 support previous work in bullfrog sympathetic neurons (Pennefather et al., 1985) and hippocampal neurons (Lancaster and Adams, 1986), indicating that there exist 2 distinct calcium-activated potassium currents, $I_{A H P}$ and $I_{C}$. Therefore, the outward current evoked by depolarizing steps will be comprised of an admixture of $I_{M}$ and 2 calcium-activated currents, $I_{A H P}$ and $I_{C}$. While $I_{M}$ and $I_{A H P}$ are blocked by carbachol, $I_{C}$ is insensitive to it.

On the basis of the above data, and from previous reports, it appears that at least 2 potassium currents in $\mathrm{CAl}$ pyramidal cells, $I_{A H P}$ and $I_{M}$, are sensitive to muscarinic agonists. We next 


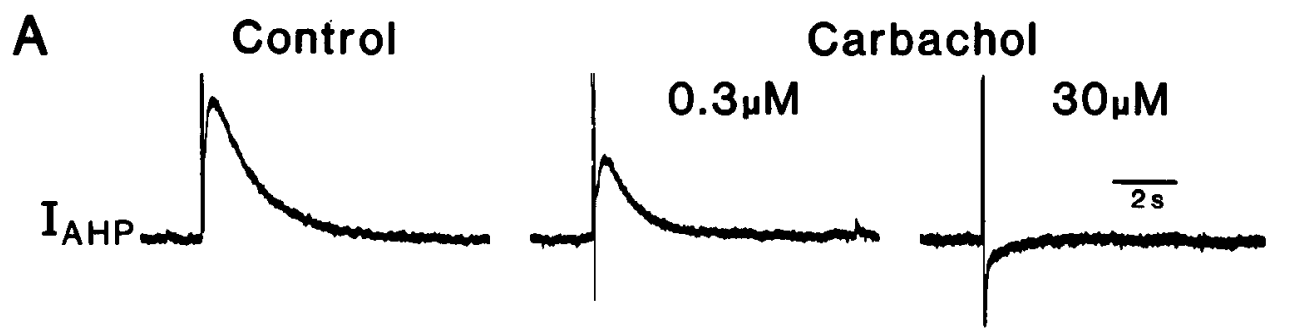

Figure 3. Sensitivity of $\mathrm{I}_{\mathrm{M}}$ and $\mathrm{I}_{\mathrm{AHP}}$ to carbachol. The records in $A$ are from the same pyramidal cell. $A, T o p$ : AHP current elicited by a short depolarizing step from a holding potential of -60 $\mathrm{mV}$ in control and 2 doses of carbachol (cumulative). Bottom: $\mathbf{M}$ current recorded concurrently with hyperpolarizing steps from a $V_{H}$ of $-45 \mathrm{mV} . B$, Concentration-response curve for carbachol (log scale) versus percentage inhibition of $\mathrm{I}_{M}$ (closed circle) and $\mathrm{I}_{\mathrm{AHP}}$ (open circle). The numeral beside each point is the number of cells in which the mean effect of that dose of carbachol was measured. Values shown are mean (or means) $\pm \mathrm{SEM}$. Note that the $\mathrm{IC}_{30}$ for carbachol versus $\mathrm{I}_{\mathrm{AHP}}$ (approximately $0.3 \mu \mathrm{M}$ ) is about 10 -fold lower than the $\mathrm{IC}_{s 0}$ for carbachol versus $\mathrm{I}_{M}(5$ $\mu \mathrm{M})$.

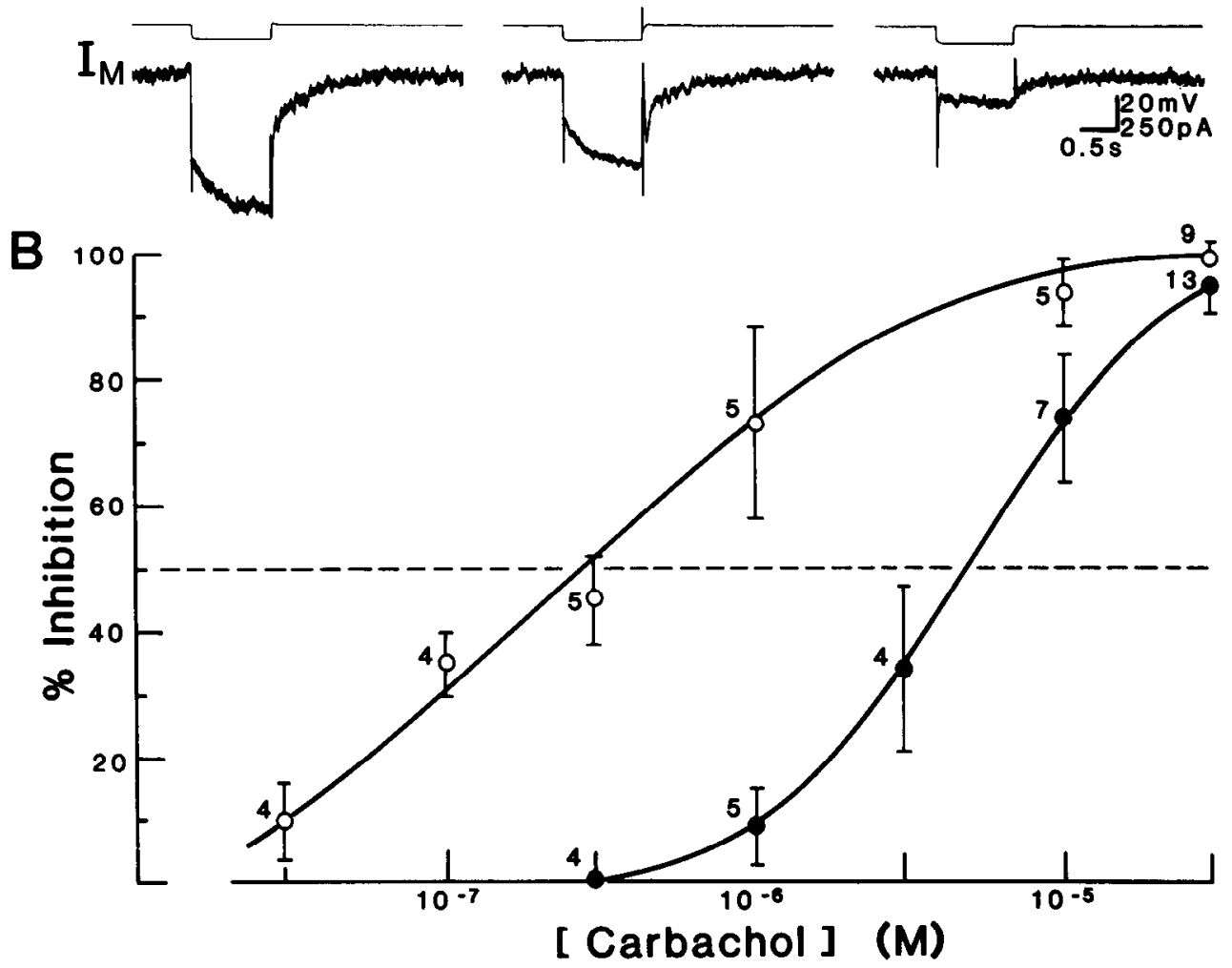

performed experiments to determine whether these 2 currents differed in their sensitivities to cholinergic agonists. We accomplished this by constructing concentration-response curves for carbachol versus $I_{M}$ and $I_{A H P}$. The mean effect of carbachol in each cell tested was determined, and the means averaged to give the curve shown in Figure $3 B$. As can clearly be seen, $\mathrm{I}_{\mathrm{AHP}}$ is significantly more sensitive to carbachol than is $\mathrm{I}_{\mathrm{M}}$. The $\mathrm{IC}_{50}$ for carbachol action against $I_{A H P}$ is approximately $0.3 \mu \mathrm{M}$, while against $I_{M}$ it was 10 -fold higher at approximately $5 \mu \mathrm{M}$. An example of the differing sensitivities of these 2 currents to carbachol is presented in Figure $3 A$. Here, $0.3 \mu \mathrm{M}$ carbachol has caused a marked reduction in $\mathrm{I}_{\mathrm{AHP}}$, while in the same cell the $M$ current relaxation is unaffected (though membrane conductance is reduced). A higher dose of carbachol $(30 \mu \mathrm{M})$ abolishes $\mathrm{I}_{\mathrm{AHP}}$ and markedly reduces $\mathrm{I}_{\mathrm{M}}$. Both actions of carbachol are reversed by atropine, which indicates that they are due to the muscarinic action of the agonist.

\section{Sensitivity of membrane currents to synaptically released $A C h$}

In voltage clamp, the current that underlies the slow cholinergic EPSP (the EPSC) can be seen following stimulation in stratum oriens as a slowly developing inward current (Fig. 4A). We have examined the sensitivity of $I_{M}$ and $I_{A H P}$ to synaptically released
ACh by making voltage steps during this synaptic current. $\mathrm{I}_{\mathrm{AHP}}$ was measured using the hybrid current voltage clamp protocol described in Materials and Methods. As would be expected from previous work (Cole and Nicoll, 1984a) that showed that synaptically released ACh reduced the AHP recorded in current clamp, we found that $\mathrm{I}_{\mathrm{AHP}}$ was reduced during the slow EPSC (Fig. $4 B_{1}$ ). $\mathrm{I}_{\mathrm{AHP}}$ recovered to its control amplitude with the decay of the slow EPSC to baseline. During the slow EPSC, $\mathrm{I}_{\mathrm{AHP}}$ was reduced by an average of $70 \%( \pm 20 \% \mathrm{SD}, n=17)$. Both the slow EPSC and the reduction of $I_{A H P}$ were prevented by the addition of atropine to the superfusing medium (Fig. $4 B_{2}$ ).

Since $I_{A H P}$ is more sensitive to exogenously applied cholinergic agonists, it seemed likely that it would also be more sensitive to synaptically released $\mathrm{ACh}$. Indeed, while the $\mathrm{I}_{\mathrm{AHP}}$ recorded in hybrid clamp (Fig. $5 A_{1}$ ) or entirely in voltage clamp (Fig. $5 B_{1}$ ) was reduced during the slow EPSC, in the same cells the $\mathrm{M}$ current was unaffected (Fig. 5, $A_{2}, A_{3}, B_{2}$ ), although once again the resting conductance was decreased. The $\mathrm{M}$ current was entirely unaffected in 18 of 21 slices tested, and was only slightly reduced $(<15 \%)$ in 3 slices. Since slow EPSCs are usually elicited in cells with no concomitant decrease in $I_{M}$, blockade of $I_{M}$ cannot account for the production of the synaptic current.

Although the $M$ current is not normally reduced during the 


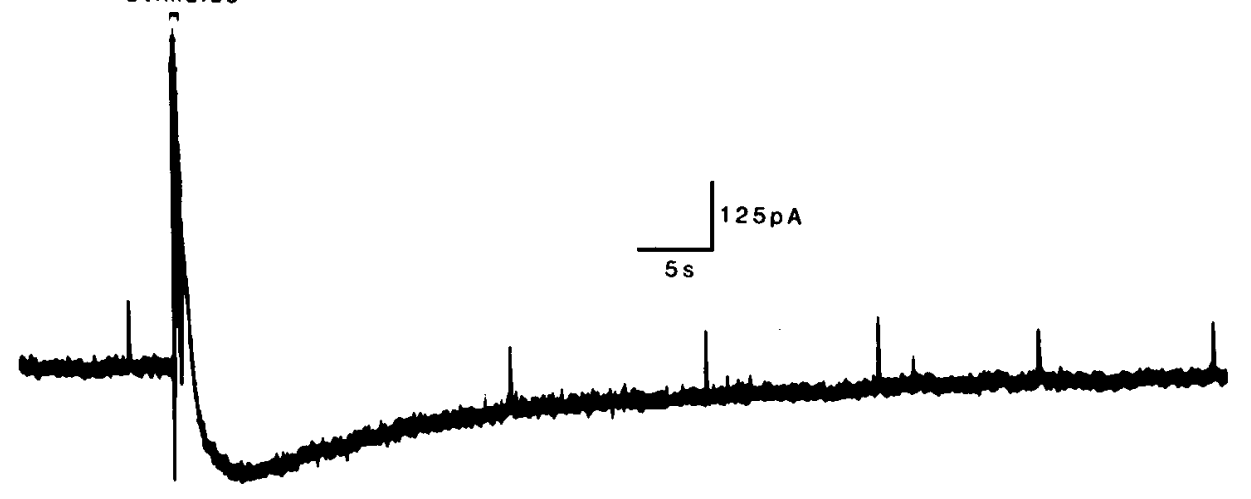

B

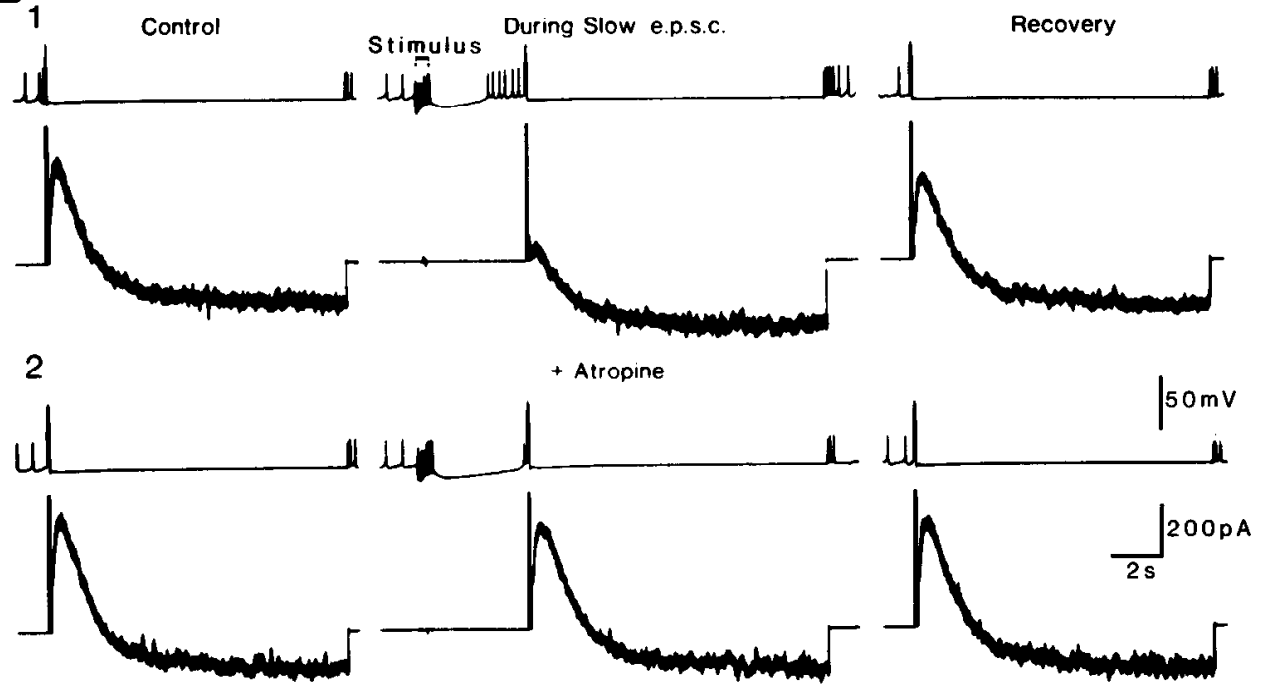

Figure 4. Cholinergic slow excitatory postsynaptic current (slow EPSC) is accompanied by a muscarinic blockade of $\mathrm{I}_{\mathrm{AHP}} . A$, Example of a slow EPSC, in a $\mathrm{CA} 1$ pyramidal cell, generated by an electrical tetanus in stratum oriens of the slice. $B$, All records in this portion of the figure were obtained using a hybrid current voltage clamp protocol (see Materials and Methods). After a tetanic stimulus was delivered to stratum oriens the $\mathrm{I}_{\mathrm{AHP}}$ was markedly reduced during the resulting slow EPSC (note inward shift in current during the slow EPSC). $I_{A H P}$ recovered to control value when the slow EPSC had decayed back to rest. Addition of atropine $(1 \mu \mathrm{M})$ to the superfusing medium while recording from the same cell blocked both the slow EPSC and the reduction of $\mathrm{I}_{\mathrm{AHP}}$ $\left(B_{2}\right)$.

course of the slow EPSC, it is sensitive to muscarinic agonists, albeit at a higher concentration than is $I_{A H P}$. It is possible, then, that reduction of $I_{M}$ by synaptically released ACh might be achieved if the concentration could be raised by blocking the activity of the degradative enzyme AChE. Thus, we tested the effects of the AChE inhibitor eserine on $\mathrm{I}_{\mathrm{M}}$ during the slow EPSC. In Figure $6 A$, a stimulus approximately 2 times the voltage necessary to elicit a slow EPSC was delivered to stratum oriens of a slice. This stimulus, while producing a large synaptic currcnt, did not cause any reduction of $I_{M}$. After addition of eserine (1 $\mu \mathrm{M}$ ) to the bathing medium (Fig. $6 B$ ), the same stimulus resulted in a synaptic current during which $I_{M}$ was reduced. Addition of carbachol to the superfusate caused an inward shift in holding current and blockade of $I_{M}$. This effect was reversed by atropine, confirming the muscarinic sensitivity of the current recorded in this experiment. After addition of atropine to the superfusate, electrical stimulation produced neither a slow EPSC nor a block of $I_{M}$, despite the continued presence of eserine.

Even though it is possible in some cells to reduce $I_{M}$ during the slow EPSP by using eserine, the fact remains that blockade of $I_{M}$ need not occur during EPSCs under normal conditions. Therefore, the next set of experiments we performed was designed to determine which current, when reduced, produced the slow EPSC. One possibility was that a resting chloride "leak" current was reduced, as has been reported for superior cervical ganglion cells (Brown and Selyanko, 1985). However, the slow EPSC was still inward when recorded with $\mathrm{KCl}$-filled microelectrodes. Therefore, the most likely ion involved in the current was potassium. Since $\mathrm{I}_{\mathrm{AHP}}$ is reduced during the slow EPSC, we first considered the possibility that blockade of a standing $I_{A H P}$ accounted for the production of this slow synaptic current. The AHP in these cells is selectively abolished by application of the membrane-permeant analog of cyclic AMP, 8-bromo cyclic AMP, or by intracellular injection of cyclic AMP itself (Madison and Nicoll, 1986b). If the slow EPSP is generated by blockade of $I_{A H P}$, then the EPSP should be abolished by prior blockade of $\mathrm{I}_{\mathrm{AHP}}$ with cyclic AMP. As shown in Figure $7 A$, an AHP was elicited in a pyramidal cell by passing a brief depolarizing current pulse through the recording electrode. In the same cell, a slow EPSP was recorded in response to stimulation in stratum oriens. Application of 8-bromo cyclic AMP (1 mM) abolished the slow AHP. However, the slow EPSP elicited in the presence of the cyclic AMP analog was of similar amplitude as in the control. Likewise, in cells recorded with cyclic AMP in the recording electrode, where the slow AHP was not present (Fig. 7B), slow EPSPs could still be elicited. Thus, we concluded that, while synaptically released $A C h$ does block $I_{A H P}$, blockade of this current could not account for the production of the slow EPSP.

Since neither blockade of $I_{M}$ nor $I_{A H P}$ could account for the slow EPSC, it was clear that another tonically active, muscarine- 
Figure 5. Calcium-activated potassium current is reduced during the slow EPSC, while the $M$ current is unaffected. $A$, Hybrid current-voltage-clamp recording of $\mathrm{I}_{\mathrm{AHP}}$ before, during, and after a slow EPSC. $A_{2}$, Recording of the $M$ current in the same cell seen with 10 $\mathrm{mV}$ hyperpolarizing voltage steps from a $V_{H}$ of $-35 \mathrm{mV}$. Note that while $I_{A H P}$ was reduced during the slow EPSC, the $\mathrm{M}$ current was not. $A_{3}$, Plots of the instantaneous (ohmic) current $\left(\mathrm{I}_{\text {in }}\right)$ before (closed circle), during (open circle), and after (triangle) the slow EPSC. The graph on the right is the stcady state $\left(\mathrm{I}_{\mathrm{ss}}\right)$, voltage-dependent current (minus the $I_{\text {in }}$ ) for the same voltage steps. Note that $I_{M}$ was unaffected during the slow EPSC at any potential tested. $B$, Records from another pyramidal cell showing the outward current generated by a $1 \mathrm{sec}$ depolarizing step from a $V_{H}$ of $-60 \mathrm{mV}$. A substantial portion of this outward current and the succeeding tail current was due to $I_{\text {AHP. }}$. This current was reduced following tetanic stimulation of stratum oriens. In the same cell, holding at $-45 \mathrm{mV}, I_{M}$ was not reduced during the slow EPSC.
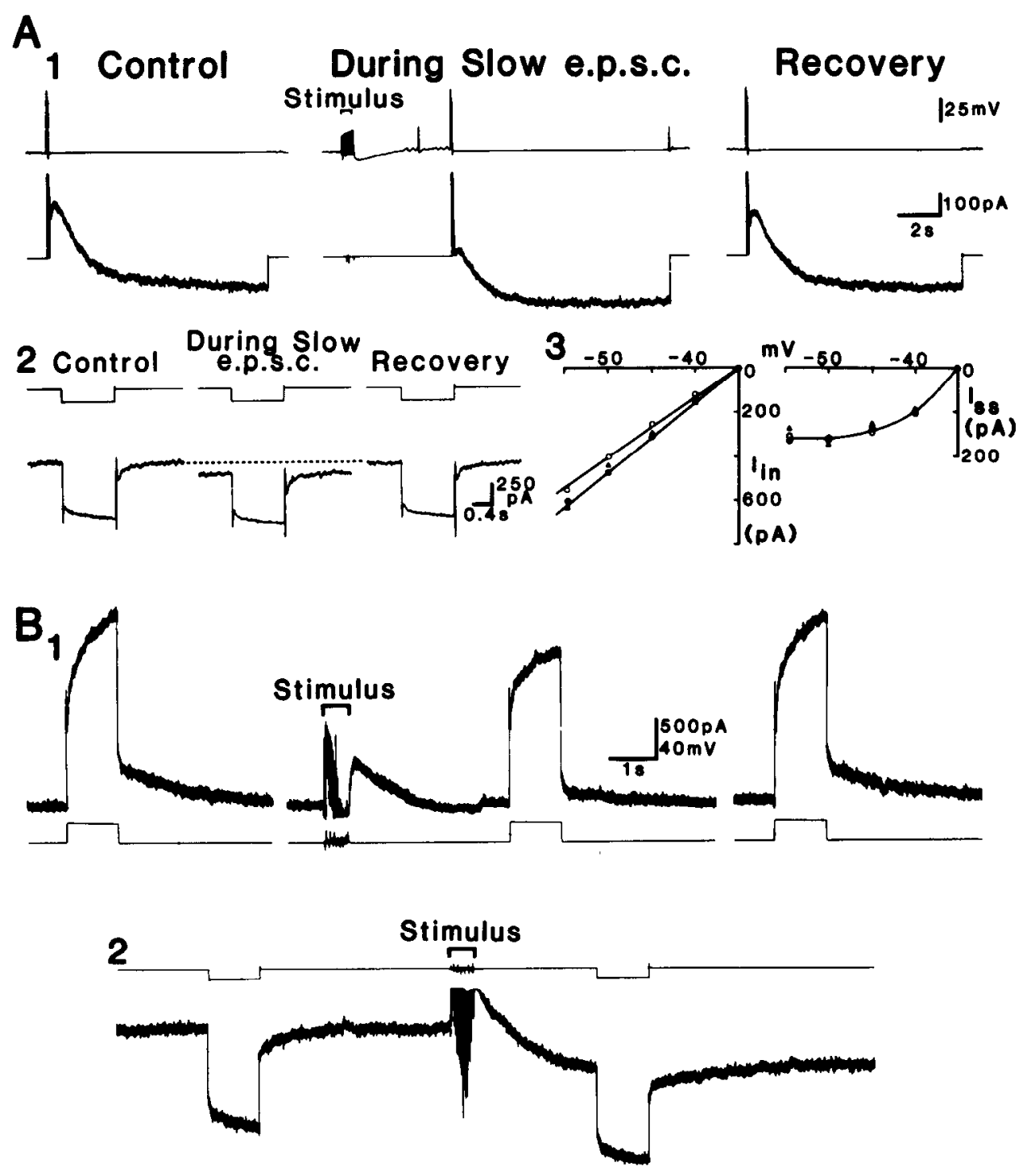

sensitive current must exist in these cells. We succeeded in gathering some information on the properties of this current. Pyramidal cells were impaled with a cyclic AMP-containing electrode to block $\mathrm{I}_{\mathrm{AHP}}$ and held in voltage clamp at negative potentials (around $-70 \mathrm{mV}$ ), where $\mathrm{I}_{M}$ is deactivated. Carbachol $(10 \mu \mathrm{M})$ applied in this condition caused a small inward current $(92+30 \mathrm{pA}, n=6$; Fig. $8 B)$ of a size similar to that of the slow EPSC. This inward current was accompanied by a decrease in membrane conductance. When the extracellular potassium concentration was raised to $15 \mathrm{~mm}$, the carbachol-induced current was reversed to an outward direction. Carbachol in high extracellular potassium produced a decrease in membrane conductance similar to that in normal (2.5 mM) potassium (Fig. $8 A$ ). By making hyperpolarizing and depolarizing voltage steps, a current-voltage plot was constructed before and after application of carbachol. Although in some cases voltage-dependent currents could be discerned during these steps, carbachol application caused a decrease only in the instantaneous current. This current had a linear current-voltage relationship and thus represents a nonrectifying "leak" potassium conductance.

\section{Discussion}

The first membrane current in hippocampal pyramidal cells to be isolated as a target for cholinergic action was the voltagesensitive current $I_{M}$ (Halliwell and Adams, 1982). Subsequently a muscarinic blockade of the slow AHP (Benardo and Prince, 1982; Cole and Nicoll, 1984b) and also a slow cholinergic EPSP were described (Cole and Nicoll, 1984a). As this EPSP was accompanied by an increase in membrane input resistance, blockade of $I_{M}$ and/or $I_{A H P}$ became logical mechanisms for the production of this synaptic potential. The present experiments were designed to shed further light on membrane currents in hippocampal pyramidal cells that are sensitive to acetylcholine, and also to identify the current blocked by muscarinic receptor activation that produces the slow EPSP. The conclusion, that 2 distinct calcium-activated potassium currents exist in these cells, is based on a previous study (Lancaster and Adams, 1986) and is further demonstrated in Figure 2. The current responsible for 

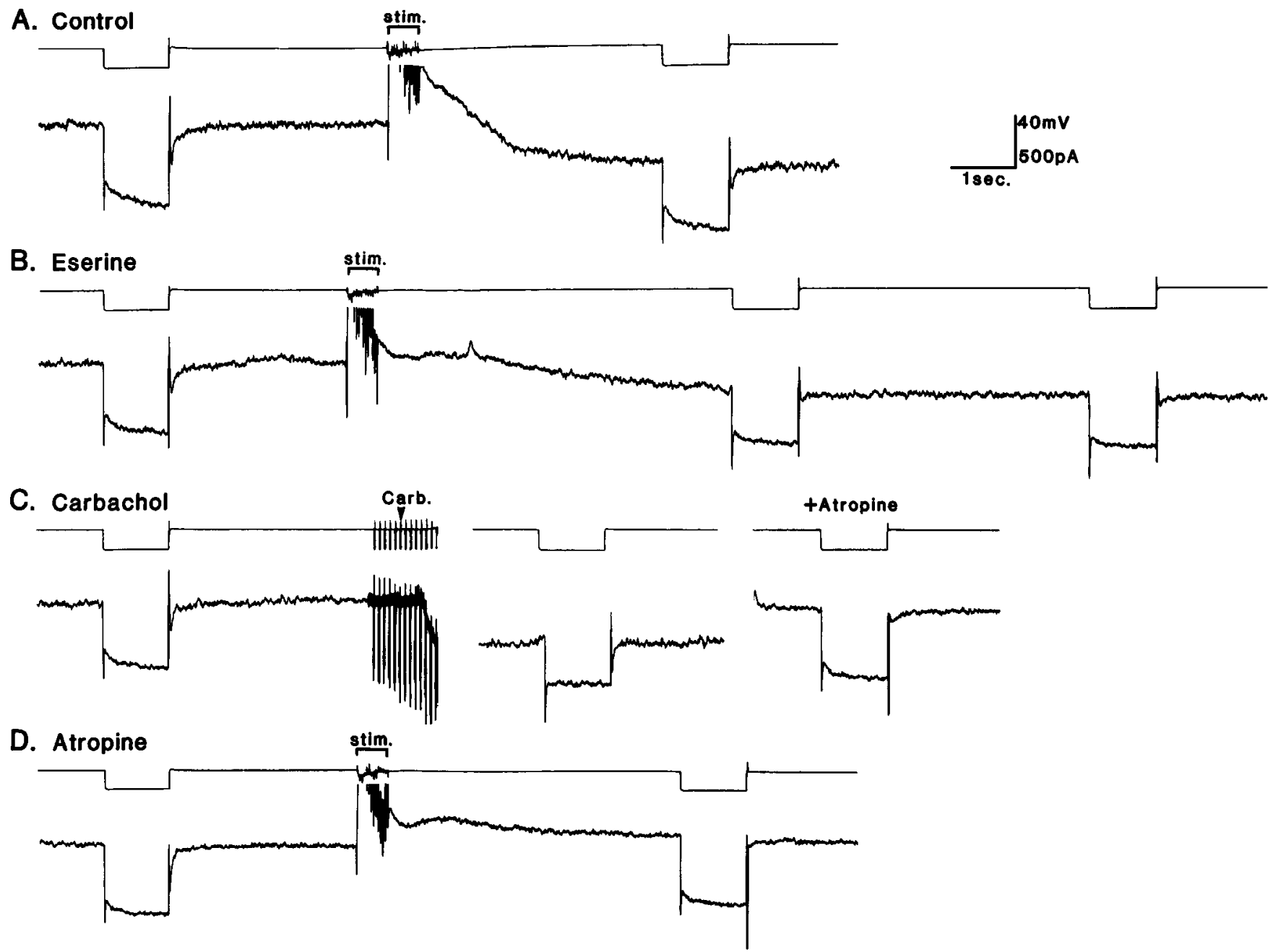

Figure 6. Effects of eserine on the slow EPSC and $\mathrm{I}_{\mathrm{M}}$. All records in this figure are from the same pyramidal cell. A, Electrical stimulation produced a slow EPSC without any reduction in $I_{M}$. After addition of eserine $(1 \mu \mathrm{M})$ to the superfusate, the same stimulus elicited a slow EPSC and the $I_{M}$ was reduced. Addition of carbachol $(30 \mu \mathrm{M})$ to the superfusate blocked the $\mathrm{M}$ current and this effect was reversed by atropine (1 $\mu \mathrm{M})$, thus confirming the muscarinic sensitivity of the current recorded here. $D$, An electrical stimulus (same as in $A$ and $B$ ) delivered in the presence of atropine (eserine still present) failed to produce a slow EPSC or a reduction in $I_{M}$.

the slow AHP (I $\left.\mathrm{I}_{\mathrm{AHP}}\right)$, and known to be caused by a calciumactivated potassium conductance, is sensitive to blockade by muscarinic receptor activation. However, in the presence of high doses of carbachol, large outward currents can still be evoked. Much of this remaining outward current is sensitive to a low concentration (1 mM) of TEA, and can also be blocked by application of the calcium channel blocker $\mathrm{Cd}^{2+}$. A similar TEAand $\mathrm{Cd}^{2+}$-sensitive current, termed $\mathrm{I}_{c}$, has been shown to be carried by $\mathrm{K}^{+}$ions (Brown and Griffith, 1983a). Thus, 2 calciumactivated $K$ currents exist-a carbachol-sensitive and a carbachol-insensitive one. This helps to account for a discrepancy in the literature. One report showed that the calcium-activated potassium AHP was blocked by muscarinic agonists (Cole and Nicoll, 1984b), while a second report demonstrated that a calcium-activated $\mathrm{K}$ current was insensitive to muscarine (Brown and Griffith, 1983a). The reason for this difference is now clear, since $I_{A H P}$, but not $I_{C}$, is carbachol-sensitive.

It is clear that $I_{A H P}$ is more sensitive to muscarinic receptor activation than is $I_{M}$, by about a factor of 10 . This is opposite to the situation in the bullfrog sympathetic ganglion, where $I_{M}$ is more muscarine-sensitive than $I_{A H P}$ (Pennefather et al.,
1985). Interestingly the higher sensitivity of $\mathrm{I}_{\mathrm{AHP}}$ to muscarinic receptor activation parallels its relative importance in spike frequency adaptation. Whereas $I_{M}$ acts as a potent brake on repetitive activity in the ganglion (Adams et al., 1982; Jones, 1985), $I_{A H P}$ is the prime source of spike frequency adaptation in the hippocampus (Madison and Nicoll, 1984). The dose profile in the hippocampus agrees with that in the olfactory cortex (Constanti and Sim, 1985). The lack of effect of synaptically released $A C h$ on $I_{M}$ can be accounted for by the lower sensitivity of this current to cholinergic agonists, although the results do not exclude differences in channel distribution with respect to the cholinergic synapses.

A conclusion of this paper is that neither blockade of $I_{M}$ nor of $\mathrm{I}_{\mathrm{AHP}}$ can account for the production of the slow EPSP. Since $\mathrm{I}_{\mathrm{M}}$ is not reduced during a slow EPSC, it cannot account for the slow synaptic current. A previous voltage-clamp study using cocultures of hippocampal and septal explants concluded that blockade of $I_{M}$ could account for much of the slow EPSC (Gahwiler and Brown, 1985). One possible explanation for these differing results is that, in the cultures, higher concentration of ACh might be reached after electrical stimulation, due perhaps 
A
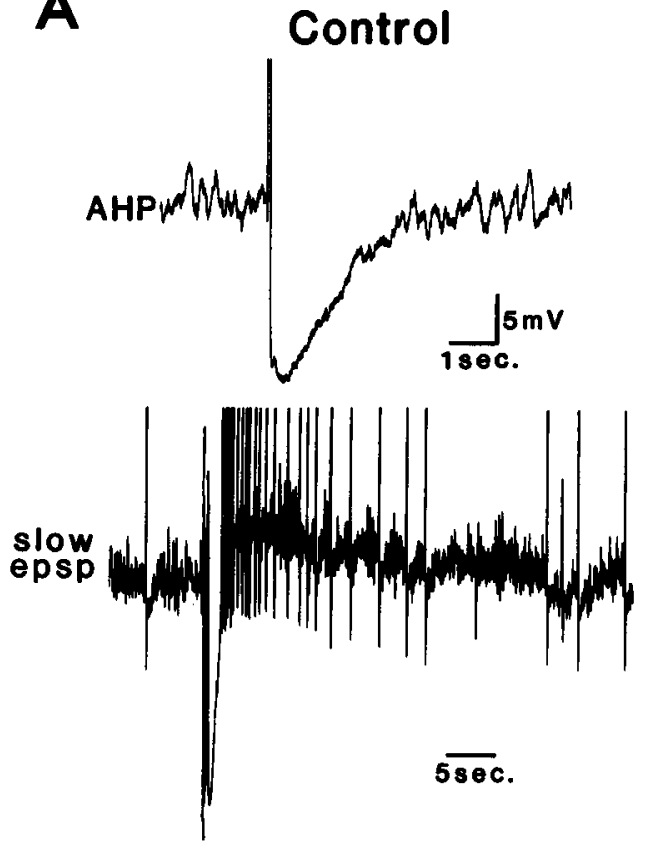
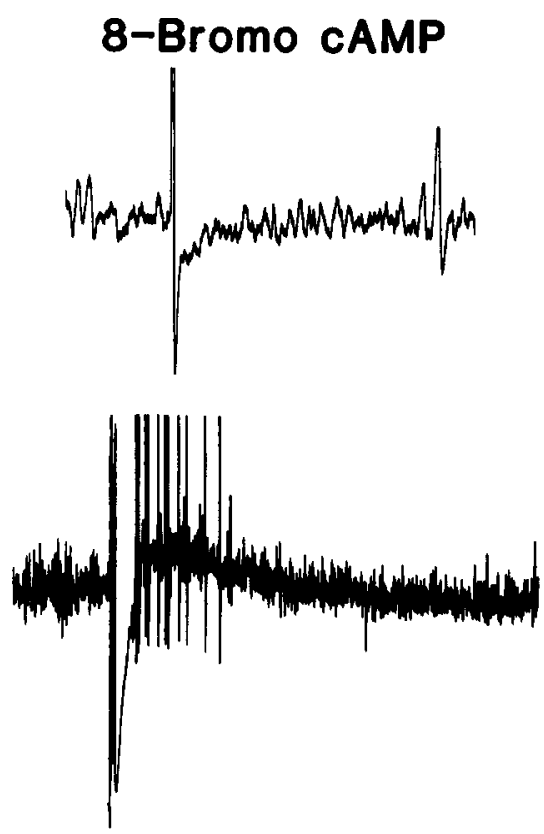

Figure 7. Blockade of $\mathrm{I}_{\mathrm{AHP}}$ cannot account for the production of the slow EPSC. A, Top row shows the AHP (in current-clamp mode) that followed a depolarization-induced burst of action potentials. The lower traces are currentclamp records of slow EPSPs in the same cell. After application of 8-bromo cyclic AMP (1 mM), the slow AHP was abolished but the slow EPSP was still present. $B$, In a cell impaled with a cyclic AMP-filled microelectrode (100 mM cyclic AMP in $3 \mathrm{M} \mathrm{KCl}$ ), no AHP could be recorded, but a slow EPSP could be elicited.

B

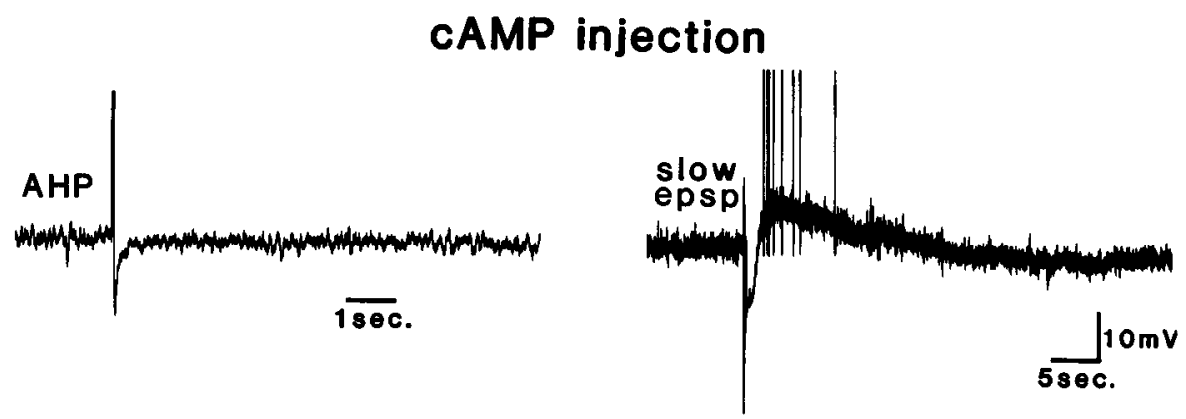

to impaired AChE activity or to hyperinnervation. Another possibility is that $\mathrm{I}_{\mathrm{AHP}}$ contributed to the outward currents evoked by the depolarizing steps in their study.

We have begun to characterize the current that generates the slow EPSC. We believe that the major ion responsible for this current is carried by potassium, since it is unaffected by changing the chloride gradient across the cell, but is sensitive to shifting the potassium gradient. The current is not due to a blockade of $I_{\text {AHP }}$, since it is unaffected by other procedures that block $I_{A H P}$. Current-voltage curves indicate that this current is not voltagesensitive. Thus we conclude that the slow EPSC is generated by a muscarinic blockade of a background potassium "leak" conductance.

While blockade of this "leak" current would promote action potential discharge, which often occurs during the slow EPSP, we believe that a far more significant consequence of synaptically released acetylcholine is the blockade of $\mathrm{I}_{\mathrm{AHP}}$, which profoundly alters the discharge properties of pyramidal cells. Furthermore, this action on the AHP and the resulting decrease in spike frequency adaptation can be observed in the absence of any change in membrane potential (Cole and Nicoll, 1984a) and is therefore a more sensitive index of muscarinic receptor activation than is the "leak" potassium conductance. Thus it can be proposed that blockade of $I_{\mathrm{AHP}}$ would be largely responsible for enhancing action potential discharge to depolarizing stimuli, while the slow EPSP, seen with higher levels of acetylcholine release, would directly promote action potential discharge.

\section{References}

Adams, P. R., A. Constanti, D. A. Brown, and R. B. Clark (1982) Intracellular $\mathrm{Ca}^{2+}$ activates a fast, voltage-sensitive $\mathrm{K}^{+}$current in vertebrate sympathetic neurones. Nature 296: 746-749.

Alger, B. E., and R. A. Nicoll (1980) Epileptiform burst after-hyperpolarization: Calcium-dependent potassium potential in hippocampal CAl pyramidal cells. Science 210: 1122-1124.

Benardo, L. S., and D. A. Prince (1982) Ionic mechanisms of cholinergic excitation in mammalian hippocampal pyramidal cells. Brain Res. 249: 333-344.

Brown, D. A., and W. H. Griffith (1983a) Calcium-activated outward current in voltage-clamped hippocampal neurones of the guinea-pig. J. Physiol. (Lond.) 337: 287-302.

Brown, D. A., and W. H. Griffith (1983b) Persistent slow inward calcium current in voltage-clamped hippocampal neurones of the guinea-pig. J. Physiol. (Lond.) 337: 303-320.

Brown, D. A., and A. A. Selyanko (1985) Two components of muscarine-sensitive membrane current in rat sympathetic neurones. J. Physiol. (Lond.) 358: 335-363.

Cole, A. E., and R. A. Nicoll (1984a) Characterization of a slow cholinergic postsynaptic potential recorded in vitro from rat hippocampal pyramidal cells. J. Physiol. (Lond.) 352: 173-188.

Cole, A. E., and R. A. Nicoll (1984b) The pharmacology of cholinergic excitatory responses in hippocampal pyramidal cells. Brain Res. 305 . 283-290. 
Control

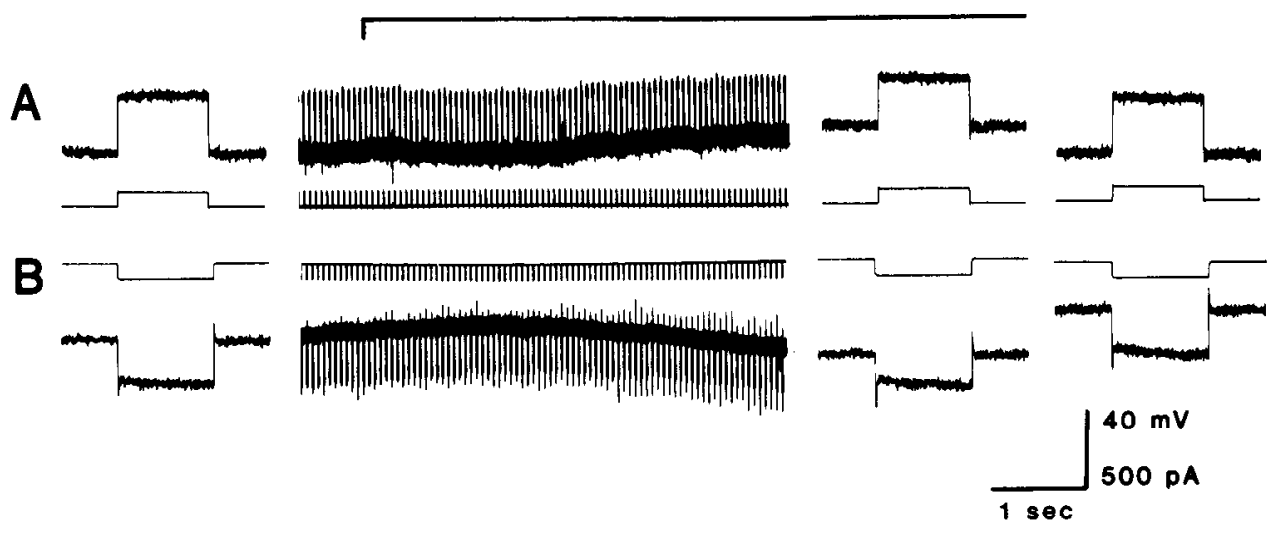

C

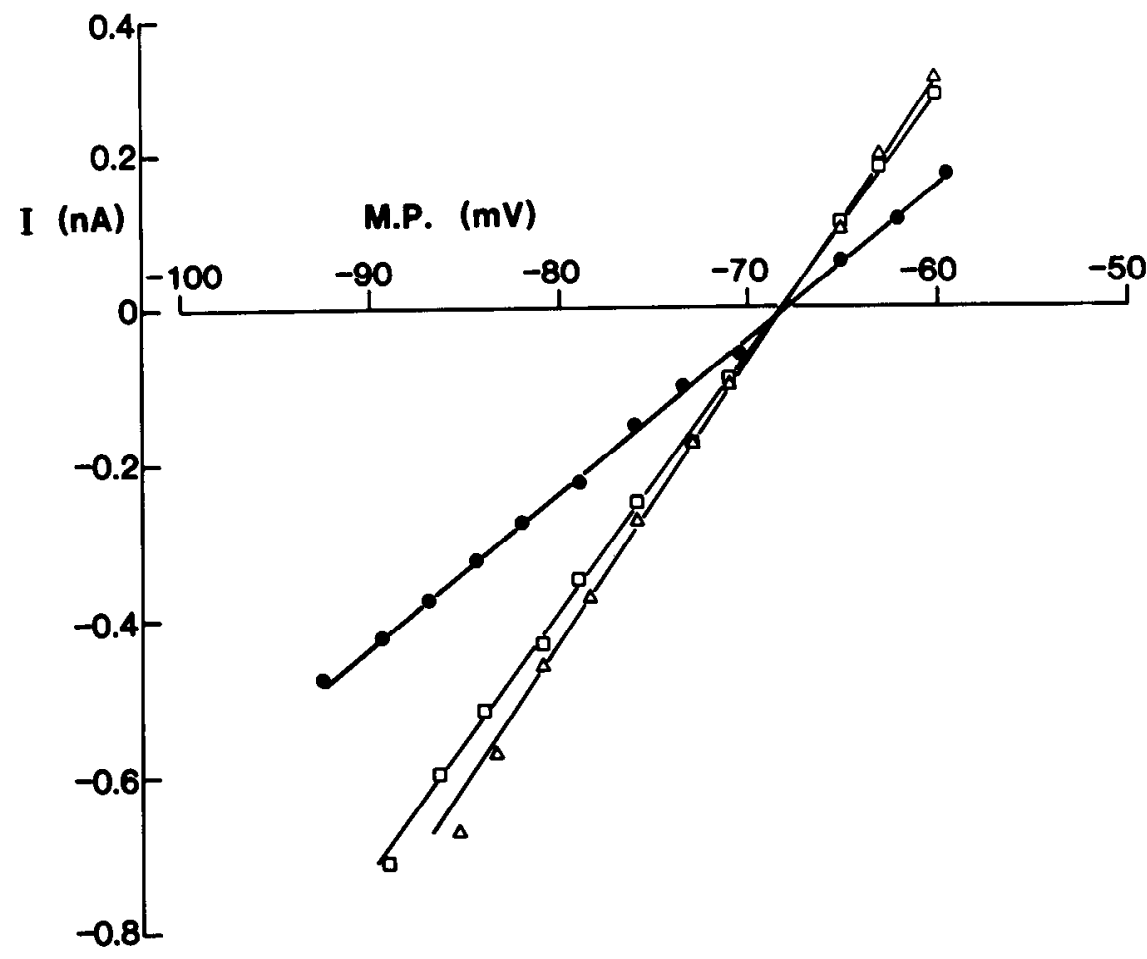

Figure 8. Carbachol decreases a resting $\mathrm{K}$ conductance. Voltage-clamp records show the action of $(A) 20 \mu \mathrm{M}$ carbachol in $15 \mathrm{mM}\left[\mathrm{K}^{+}\right]_{0}$ or $(B) 10 \mu \mathrm{M}$ carbachol in $2.5 \mathrm{mM}\left[\mathrm{K}^{+}\right]_{0}$. Records are from different cells. In $25 \mathrm{~mm} \mathrm{~K}^{+}{ }_{0}$, carbachol produced an inward current with a decrease in the resting membrane conductance $\left(\mathrm{V}_{\mathrm{H}},-68 \mathrm{mV}\right)$. In $15 \mathrm{~mm}$ $\mathrm{K}^{+}{ }_{0}$, carbachol induced an outward current, also associated with a decrease in instantaneous conductance $\left(\mathrm{V}_{\mathrm{H}},-74\right.$ $\mathrm{mV}$ ). These effects were reversed upon washing with $0.1 \mu \mathrm{M}$ atropine. Electrodes contained $3 \mathrm{M} \mathrm{KCl}$ plus $100 \mathrm{mM}$ cAMP, which eliminates $I_{A H P}$. Holding potential was maintained at a negative level to deactivate $\mathrm{I}_{\mathrm{M}} . C$, Instantaneous current-voltage plot for the cell in $B$, before (open squares) and during $10 \mu \mathrm{M}$ carbachol (closed circles), and after washing in $0.1 \mu \mathrm{M}$ atropine (open triangles). The bathing medium contained TTX $(1 \mu \mathrm{M})$.
Constanti, A., and J. A. Sim (1985) A slow, muscarine-sensitive Cadependent $\mathrm{K}$ current in guinea-pig olfactory cortex neurones in vitro. J. Physiol. (Lond.) 365: 47P.

Dodd, J., R. Dingledine, and J. S. Kelly (1981) The excitatory action of acetylcholine on hippocampal neurons of the guinea-pig and rat maintained in vitro. Brain Res. 207: 109-127.

Gahwiler, B., and D. A. Brown (1985) Functional innervation of cultured hippocampal neurones by cholinergic afferents from co-cultured septal explants. Nature 313: 577-579.

Halliwell, J. V., and P. R. Adams (1982) Voltage-clamp analysis of muscarinic excitation in hippocampal neurons. Brain Res. 250: 7192.

Johnston, D., and T. H. Brown (1983) Interpretation of voltage-clamp measurements in hippocampal neurons. J. Neurophysiol. 50: 464486.

Johnston, D., J. J. Hablitz, and W. A. Wilson (1980) Voltage clamp discloses slow inward current in hippocampal burst-firing neurones. Nature 286: 391-393.

Jones, S. W. (1985) Muscarinic and peptidergic excitation of bull-frog sympathetic neurones. J. Physiol. (Lond.) 366: 63-88.

Lancaster, B., and P. R. Adams (1986) Calcium-dependent current generating the afterhyperpolarization of hippocampal neurons. J. Neurophysiol. 55: 1268-1282.
Lewis, P. R., and C. C. D. Shute (1967) The cholinergic limbic system: Projections to hippocampal formation, medial cortex, nuclei of the ascending cholinergic reticular system and the subfornical organ and supraoptic crest. Brain 90: 521-540.

Madison, D. V., and R. A. Nicoll (1984) Control of the repetitive discharge of rat CA1 pyramidal neurones in vitro. J. Physiol. (Lond.) 354: 319-331.

Madison, D. V., and R. A. Nicoll (1986a) Actions of noradrenaline recorded intracellularly in rat hippocampal CA1 pyramidal neurones. J. Physiol. (Lond.) 372: 221-244.

Madison, D. V., and R. A. Nicoll (1986b) Cyclic adenosine 3',5'monophosphate mediates beta-receptor actions of noradrenaline in rat hippocampal pyramidal cells. J. Physiol. (Lond.) 372: 245-259.

Madison, D. V., B. Lancaster, R. A. Nicoll, and P. R. Adams (1985) Voltage clamp analysis of slow cholinergic synaptic transmission in the hippocampus. Neurosci. Abstr. 11: 467.

Nicoll, R. A. (1985) The septo-hippocampal projection: A model cholinergic pathway. Trends Neurosci. 8: 533-536.

Nicoll, R. A., and B. E. Alger (1981) A simple chamber for recording from submerged brain slices. J. Neurosci. Methods 4: 153-156.

Pennefather, P., B. Lancaster, P. R. Adams, and R. A. Nicoll (1985) Two distinct $\mathrm{Ca}$-dependent $\mathrm{K}$ currents in bullfrog sympathetic ganglion cells. Proc. Natl. Acad. Sci. USA 82: 3040-3044. 